Article

\title{
Species-Specific Paternal Age Effects and Sperm Methylation Levels of Developmentally Important Genes
}

\author{
Andreas Prell ${ }^{1,+}$, Mustafa Orkun Sen ${ }^{1,+}$, Ramya Potabattula ${ }^{1,+} \mathbb{D}$, Laura Bernhardt ${ }^{1} \mathbb{D}$, Marcus Dittrich ${ }^{1,2}$, \\ Thomas Hahn ${ }^{3}$, Martin Schorsch ${ }^{3}$, Federica Zacchini ${ }^{4,5}, 6$, Grazyna Ewa Ptak ${ }^{5}$, Heiner Niemann ${ }^{7}$ \\ and Thomas Haaf $1, * \mathbb{D}$
}

\section{check for}

updates

Citation: Prell, A.; Sen, M.O.;

Potabattula, R.; Bernhardt, L.

Dittrich, M.; Hahn, T.; Schorsch, M.; Zacchini, F.; Ptak, G.E.; Niemann, H.; et al. Species-Specific Paternal Age Effects and Sperm Methylation Levels of Developmentally Important Genes. Cells 2022, 11, 731. https:// doi.org/10.3390/cells11040731

Academic Editors: Salvatore Fusco, Gerda Egger and Maria Rita Rippo

Received: 15 December 2021

Accepted: 15 February 2022

Published: 19 February 2022

Publisher's Note: MDPI stays neutral with regard to jurisdictional claims in published maps and institutional affiliations.

Copyright: (c) 2022 by the authors. Licensee MDPI, Basel, Switzerland This article is an open access article distributed under the terms and conditions of the Creative Commons Attribution (CC BY) license (https:// creativecommons.org/licenses/by/ $4.0 /)$.
1 Institute of Human Genetics, Julius Maximilians University, 97074 Würzburg, Germany; andreas.prell@stud-mail.uni-wuerzburg.de (A.P.); mustafa_orkun.sen@stud-mail.uni-wuerzburg.de (M.O.S.); ramya.potabattula@uni-wuerzburg.de (R.P.); laura.bernhardt@uni-wuerzburg.de (L.B.); marcus.dittrich@biozentrum.uni-wuerzburg.de (M.D.)

2 Department of Bioinformatics, Julius Maximilians University, 97074 Würzburg, Germany

3 Fertility Center, 65189 Wiesbaden, Germany; th.hahn@mail.de (T.H.); martin.schorsch@gmx.de (M.S.)

4 PERCUROS BV, 2333 CL Leiden, The Netherlands; f.zacchini@percuros.nl

5 Malopolska Centre of Biotechnology, Jagiellonian University, 30-387 Krakow, Poland; g.ptak@uj.edu.pl

6 Wolfson Centre for Age-Related Diseases, King's College London, London SE1 1UL, UK

7 Clinic for Gastroenterology, Hepatology and Endocrinology, Medical University Hannover, 30625 Hannover, Germany; niemann.heiner@mh-hannover.de

* Correspondence: thomas.haaf@uni-wuerzburg.de; Tel.: +49-931-3188738

+ These authors contributed equally to the manuscript.

\begin{abstract}
A growing number of sperm methylome analyses have identified genomic loci that are susceptible to paternal age effects in a variety of mammalian species, including human, bovine, and mouse. However, there is little overlap between different data sets. Here, we studied whether or not paternal age effects on the sperm epigenome have been conserved in mammalian evolution and compared methylation patterns of orthologous regulatory regions (mainly gene promoters) containing both conserved and non-conserved CPG sites in 94 human, 36 bovine, and 94 mouse sperm samples, using bisulfite pyrosequencing. We discovered three (NFKB2, RASGEF1C, and RPL6) age-related differentially methylated regions (ageDMRs) in humans, four (CHD7, HDAC11, PAK1, and $P T K 2 B)$ in bovines, and three (Def6, Nrxn2, and Tbx19) in mice. Remarkably, the identified sperm ageDMRs were all species-specific. Most ageDMRs were in genomic regions with medium methylation levels and large methylation variation. Orthologous regions in species not showing this age effect were either hypermethylated $(>80 \%)$ or hypomethylated $(<20 \%)$. In humans and mice, ageDMRs lost methylation, whereas bovine ageDMRs gained methylation with age. Our results are in line with the hypothesis that sperm ageDMRs are in regions under epigenomic evolution and may be part of an epigenetic mechanism(s) for lineage-specific environmental adaptations and provide a solid basis for studies on downstream effects in the genes analyzed here.
\end{abstract}

Keywords: age-related differentially methylated regions (ageDMRs); bisulfite pyrosequencing; mammalian male germline; paternal age effect; species-specific epigenetic marks; sperm DNA methylation

\section{Introduction}

The sperm epigenome is the end product of male germline reprogramming, which is affected by stochastic and environmental factors, including male infertility, paternal diet, and aging [1,2]. The methylation status of promoter elements and other regulatory regions is critically involved in shaping gene expression profiles during development and differentiation [3]. Accumulating evidence indicates that the sperm methylome affects the embryo development and disease susceptibility of the resulting offspring [4-6]. 
Historically, medical problems associated with delayed parenthood were primarily attributed to maternal aging. The decreasing ovarian reserve and increasing oocyte aneuploidy rate are associated with serious fertility problems, miscarriages, and children with Down syndrome [7]. However, the developmental potential of sperm from aging men is also reduced [8]. The increasing rate of de novo genetic mutations in the offspring of older males elevates the risks for some rare monogenic [9] and complex, in particular, neurodevelopmental disorders [10]. The number of spermatogonial cell divisions increases from 35 times at puberty to $>800$ times at the age of 50 years [9]. During each replication cycle, not only the DNA sequence itself, but also epigenetic marks must be correctly copied to the daughter cells. Since the error rate of this copying process is estimated to be 10-100 times higher for epigenetic than for genetic information [11], the spermatozoa from older males have accumulated many more epimutations than DNA sequence mutations. In the aging mouse model, sperm DNA methylation changes have been associated with changes in gene methylation and expression in the brain and abnormal behavior in the offspring derived from older males [12].

The age-related gain in ribosomal DNA (rDNA) methylation reflects functional changes in nucleolar biology during aging and in age-related conditions [13,14]. Moreover, the correlation between rDNA methylation and aging has been conserved across a broad spectrum of somatic tissues and in the male germline in different mammalian species [2,15]. This evolutionary conservation is generally considered a good indicator of functional significance.

Paternal age effects have been extensively studied in the human [4,16-18], bovine [19-21], and mouse $[12,22,23]$ sperm methylomes. Several epigenetic clocks, derived by linear regression algorithms on different methylation array data, have been successfully used for human sperm age prediction [16-18,24]. However, there is little overlap between the identified ageDMRs in different data sets and the highly selected CpGs (scattered throughout the genome) for different epigenetic clocks. The sperm epigenome has undergone extensive genome-wide methylation reprogramming in the male germline [25], which may explain the small intersection between age-related CpGs in sperm and somatic tissues such as blood [26,27].

In humans, CpGs susceptible to age-related sperm methylation changes appear to be enriched in the proximity of genes thought to be critically involved in embryogenesis and neuronal development, thereby supporting a role for the aging sperm methylome on reduced developmental potential and increased life-long disease risk of the offspring $[4,17]$. However, the relationship between the highly selected target CpGs of different epigenetic clocks and the aging process remains an enigma [26,27]. The goal of our study was to test whether the paternal age effect exists at the single-gene level of orthologous regulatory regions in humans, bovines, and mice.

\section{Materials and Methods}

\subsection{Study Samples}

The study on human (Homo sapiens, HSA) sperm samples was approved by the ethics committee at the medical faculty of the University of Würzburg (no. 117/11 and 212/15). After in vitro fertilization (IVF) or intracytoplasmic sperm injection (ICSI) at the Fertility Center Wiesbaden, the left-over swim-up sperm fraction (excess material) was collected, pseudonymized, and frozen at $-80^{\circ} \mathrm{C}$ until further use. To eliminate contamination by bacteria, lymphocytes, epithelial, and other somatic cells, the swim-up sperm samples were gently thawed and purified further by density gradients PureSperm 80 and 40 (Nidacon, Mölndal, Sweden). The vast majority (92 of 94) of sperm samples were from males with normal semen parameters.

Thirty-six sperm samples from 15 high-performance breeding bulls (Bos taurus, BTA) were obtained from Masterrind, Verden, Germany. Two or three samples (collected at young, middle, and old age) were available from 12 bulls. Bull sperm samples were purified by BoviPure and BoviDilute (Nidacon). Ninety-four mouse (Mus musculus, MMU) 
sperm samples were isolated from 3 to 16 -month-old mice after cervical dislocation. The vas deferens and caudal epididymis were dissected and placed separately into $500 \mu \mathrm{L}$ GMOPS with $10 \mathrm{mg} / \mathrm{mL}$ human serum albumin at $37^{\circ} \mathrm{C}$. Swim-up sperm purification was performed, and the final fraction was washed twice with PBS and resuspended in $500 \mu \mathrm{L}$ $1 \times$ PBS.

For DNA isolation, the purified sperm cells were resuspended in $300 \mu \mathrm{L}$ buffer $(5 \mathrm{~mL}$ of $5 \mathrm{M} \mathrm{NaCl}, 5 \mathrm{~mL}$ of $1 \mathrm{M}$ Tris-HCl; $\mathrm{pH} 8,5 \mathrm{~mL}$ of $10 \%$ SDS; $\mathrm{pH} 7.2,1 \mathrm{~mL}$ of $0.5 \mathrm{M}$ EDTA; $\mathrm{pH} 8,1 \mathrm{~mL}$ of $100 \% \beta$-mercaptoethanol, and $33 \mathrm{~mL}$ of $\left.\mathrm{H}_{2} \mathrm{O}\right)$, and $100 \mu \mathrm{L}(20 \mathrm{mg} / \mathrm{mL}$; $600 \mathrm{mAU} / \mathrm{mL}$ ) proteinase K (Qiagen, Hilden, Germany), and incubated for $2 \mathrm{~h}$ at $56^{\circ} \mathrm{C}$. Sperm DNA was isolated using the DNeasy Blood and Tissue kit (Qiagen). DNA concentration and purity were measured by NanoDrop 2000c spectrophotometer (Thermo Scientific, MA, USA). Bisulfite conversion was carried out using the EpiTect Fast 96 Bisulfite kit (Qiagen) following the manufacturer's recommendations. Bisulfite-converted DNA samples were stored at $-20^{\circ} \mathrm{C}$ until further use.

\subsection{Study Genes}

Candidate genes were selected from an in-house data bank, based on reduced representation bisulfite sequencing (RRBS) on 73 human, 16 bovine, and 24 mouse sperm samples (unpublished results). Three genes, NFKB2, RASGEF1C, and RPL6, were selected from a preliminary list of ageDMRs in human sperm. Similarly, four genes, $C H D 7$, HDAC11, PAK1, and PTK2B, were selected from the bovine and three, Def6, Nrxn2, and $T b x 19$, from the mouse list (Table S1). Orthologous regions in the human, bovine, and mouse ageDMRs as well as conserved CpG sites in the three studied species were identified with the Ensembl BLAST tool. Genome Reference Consortium Human Build 38 (GRCh38)/hg38, ARS-UCD1.2/bosTau9, and Genome Reference Consortium Mouse Build 38 (GRCm38)/mm10 were used as reference genomes. It is important to note that there is no information on the methylation levels of the identified sperm ageDMRs in other tissues or cell types.

\subsection{Bisulfite Pyrosequencing}

Polymerase chain reaction (PCR) and sequencing primers (Table S2) for orthologous human, bovine, and mouse amplicons were designed using the Pyro-Mark Assay Design 2.0 software (Qiagen). DNA methylation standards with $0 \%, 50 \%$, and $100 \%$ methylation were used for assay establishment. PCR for each sample was performed in a $25 \mu \mathrm{L}$ reaction consisting of $2.5 \mu \mathrm{L} 10 \times$ PCR buffer with $\mathrm{MgCl}_{2}, 0.5 \mu \mathrm{L}(10 \mathrm{mM}) \mathrm{dNTPs}, 1.25 \mu \mathrm{L}$ $(10 \mathrm{pmol} / \mathrm{mL})$ of each reverse and forward primer, $0.2 \mu \mathrm{L}(5 \mathrm{U} / \mu \mathrm{L})$ FastStart Taq DNA polymerase (Roche Diagnostics, Mannheim, Germany), $1 \mu \mathrm{L}$ ( $25 \mathrm{ng}$ ) bisulfite-converted DNA and $18.3 \mu \mathrm{L} \mathrm{dH}_{2} \mathrm{O}$. PCR amplifications were carried out with an initial denaturation at $95{ }^{\circ} \mathrm{C}$ for $5 \mathrm{~min}, 35$ cycles of $95^{\circ} \mathrm{C}$ for $30 \mathrm{~s}$, primer-specific annealing temperature (Table S2) for $30 \mathrm{~s}$, and $72{ }^{\circ} \mathrm{C}$ for $45 \mathrm{~s}$, and a final extension step at $72{ }^{\circ} \mathrm{C}$ for $10 \mathrm{~min}$. Pyrosequencing was carried out using Pyro Q-CpG software (Qiagen) and PyroMark Gold Q96 CDT reagent kit on the PyroMark Q96 MD system. Unmethylated and fully methylated DNA standards (Qiagen) were used as controls in each pyrosequencing run.

\subsection{Statistical Analysis}

Statistical analysis was performed using IBM SPSS version 26. The donor age was correlated with the sperm DNA methylation level of the corresponding amplicon at the individual CpG and the regional level. For human samples, Pearson's partial correlations were applied to adjust for possible confounding factors such as sperm concentration and donor body mass index. Depending on the data distribution, Spearman's correlations were used for bovine and mouse samples. A $p$ value of $<0.05$ was considered as statistically significant throughout the analyses. To compare age-related methylation changes in orthologous regions across species, methylation of a given sample was adjusted to the 
lifespan, which is largely different between mice (28 months), bulls (20 years), and humans (80 years).

\section{Results}

Using bisulfite pyrosequencing in 94 human, 36 bovine, and 94 mouse sperm samples, to screen candidate genes for paternal age effects, we identified a number of ageDMRs in the human (NFKB2, RASGEF1C, and RPL6), bovine (CHD7, HDAC11, PAK1, and PTK2B), and mouse (Def6, Nrxn2, and Tbx19) sperm epigenomes, respectively. The DMRs were in the promoter (7 of 10), promoter-flanking (1 of 10$)$, or regulatory (1 of 10$)$ regions (Table S1). The encoded genes are involved in transcriptional regulation, signaling, and neurodevelopment. Because of the rather high $\mathrm{CpG}$ mutation rate, even in the absence of DNA methylation $[28,29]$, the orthologous regions in humans, bovines, and mice contain both evolutionarily conserved and non-conserved CpGs (Table 1). The donor age ranged from 29 to 72 years (mean $\pm \mathrm{SD} ; 39.3 \pm 5.9$ ) in humans, from one to 12 years $(4.8 \pm 3.1)$ in bovines, and from 3 to 16 months $(8.9 \pm 3.7)$ in mice. For humans, body mass index ranged from 19 to $32 \mathrm{~kg} / \mathrm{m}^{2}(25.6 \pm 2.9)$ and sperm concentration was from 15 to $260 \mathrm{million} / \mathrm{mL}$ $(84.5 \pm 45.8)$.

Since, usually, the density of methylated CpGs, rather than individual CpGs in the promoter or a regulatory region, turns a gene "on" or "off" [30], we first compared the average methylation of all CpGs in a target region between species (Table 2). Average sperm methylation of orthologous regions (mainly gene promoters) was not conserved across species. For example, NFKB2, RASGEF1C, and RPL6, which were endowed with human ageDMRs, displayed medium sperm methylation (20-80\%) in humans, whereas the orthologous regions in bovines and mice were either hypermethylated $(>80 \%)$ or hypomethylated $(<20 \%)$. Similar was true for genes with bovine ageDMRs (CHD7, HDAC11, PAK1, and PTK2B) and mouse ageDMRs (Def6, Nrxn2, and Tbx19), respectively.

Next, we determined the correlation between donor age and the average methylation of orthologous regions for the 10 study genes (Figure 1). For a better graphical representation of the species-specific age effects, donor age was adjusted to the percentage of lifespan. Significant or highly significant age effects were observed for NFKB2, RASGEF1C, and RPL6 in human sperm samples; for CHD7, HDAC11, PAK1, and PTK2B in bovine sperm samples; and for Def6, Nrxn2, and Tbx19 in mouse sperm samples (Table 3). Strikingly, none of the 10 sperm ageDMRs were evolutionarily conserved. Either there was no significant correlation with donor age in the two other analyzed species (for example, see human RPL6) or we found a significant effect in the opposite direction (for example, see mouse Def6 and Tbx19).

Finally, we performed correlation analyses of individual conserved CpGs (Figure S1; Table S3). With one notable exception, results were identical to the regional methylation analysis. At the regional level, Nrxn2 sperm methylation showed a significant negative correlation with donor age in mice, whereas no significant age effects were observed in humans and bovines (Figure 1; Table 3). The evolutionarily conserved NRXN2 CpG in MMU19:6,504,094; HSA11:64,636,329, and BTA29:42,885,109 showed a highly significant $(p<0.001)$ loss of methylation in mice and humans, but not in bovines. Age-related methylation changes in the remaining 29 analyzed evolutionarily conserved CpG sites (in 10 genes) were all species-specific.

Although we cannot exclude the possibility of a selection bias, it is conspicuous that human and mouse sperm DMRs were negatively correlated with age, whereas bovine DMRs gained methylation with age (Figure 1, Table 3). Moreover, ageDMRs usually displayed medium methylation levels associated with considerable methylation variation. Hypermethylated and hypomethylated regions showed less methylation variation and appeared to be more resistant to paternal age effects. 
Table 1. Genes, genomic regions, and CpG sites that have been analyzed in human (HSA), bovine (BTA), and mouse (MMU) sperm.

\begin{tabular}{|c|c|c|c|}
\hline Gene & Species & Genomic Localization $^{\text {a }}$ & Sequence Analyzed by Bisulfite Pyrosequencing ${ }^{b}$ \\
\hline \multicolumn{4}{|c|}{ Human ageDMRs } \\
\hline \multirow{2}{*}{ NFKB2 } & HSA & \multirow{2}{*}{$\begin{array}{c}\text { chr10: } 102,398,797-102,398,849 \\
\text { chr19: } 46,308,687-46,308,739\end{array}$} & CG GGGGTGGCTCCCACATGGGTGGAGGCTCTGGGGGTGCAGC CG GGGGCTA CG \\
\hline & MMU & & CG GGGG CG GATCCCACATGGGTGGAGGTTCTGGGGGCTC CG CTGGGGGTTATG \\
\hline \multirow{2}{*}{ RASGEF1C } & HSA & \multirow{2}{*}{$\begin{array}{c}\text { chr5: } 180,128,402-180,128,452 \\
\text { chr11: } 49,960,606-49,960,556\end{array}$} & CG GCTTACCAGTTCCA CG TGGGTCAGCTGCTGGGCCAGTGTGTAGGGGT CG \\
\hline & MMU & & CCACTCACCAGCTCCA CG TGGGTCAGTTGCTGGGCCAG CG TGTAGGGGTCA \\
\hline \multirow{3}{*}{ RPL6 } & HSA & \multirow{3}{*}{$\begin{array}{c}\text { chr12: } 112,408,273-11,240,8247 \\
\text { chr17: } 61,838,759-61,838,785 \\
\text { chr5: } 121,205,822-121,2058,48\end{array}$} & CG G CG GTACC CG GGTGGTTAAACTT CG \\
\hline & BTA & & TGGTGGTACC CG AGTGGTCAAACTT CG \\
\hline & MMU & & CG GTGGCACC CG GGTGGTGAAGCTT CG \\
\hline \multicolumn{4}{|c|}{ Bovine ageDMRs } \\
\hline \multirow{3}{*}{ CHD7 } & BTA & chr14: $26,361,243-26,361,288$ & CTAGG CG GTTACCTGGCC CG GGGGGACTTCTCCATGC CG CAGCATG \\
\hline & HSA & chr8: $60,741,997-60,742,042$ & ATGGGCAGCTATATGGCA CG TGGGGATTTTTCCATGCAGCAGCATG \\
\hline & MMU & chr4: 8,752,051-8,752,096 & ATGGGCAGCTATCTGGCA CG TGGGGATTTCTCCATGCAGCAGCA CG \\
\hline \multirow{2}{*}{ HDAC11 } & BTA & \multirow{2}{*}{$\begin{array}{c}\text { chr22: } 58,440,641-58,440,716 \\
\text { chr3: } 13,481,361-13,481,287\end{array}$} & CG GCGTC[ ... ]AG CG CG G CG AGTACA CG ATGGGCCAG CG \\
\hline & HSA & & CG GCATC[ ... ]AG CG CG G CG AGTACA CG ATTGGCCAG CG \\
\hline \multirow[t]{2}{*}{ PAK1 } & HSA & \multirow{2}{*}{$\begin{array}{c}\text { chr29: } 18,586,633-18,586,667 \\
\text { chr11: } 77,411,828-77,411,794 \\
\text { chr7: } 97,843,083-97,843,117\end{array}$} & CG GCTCTG CG ACGGAAACAAT CG CCAGAGATGC CG \\
\hline & MMU & & CG GCTCTG CG ACAGATACACAAGATCATCAGAGAT \\
\hline \multirow{2}{*}{ PTK2B } & BTA & chr8: 74,491,018-74,490,993 & CG A CG TAATGTGCCCACCTTCACT CG \\
\hline & HSA & chr8: $27,397,637-27,397,612$ & CG G CG TAA CG TGCCCAACTTTACT CG \\
\hline \multicolumn{4}{|c|}{ Mouse ageDMRs } \\
\hline \multirow{3}{*}{ Def6 } & MMU & \multirow{3}{*}{$\begin{array}{c}\text { chr17: } 28,217,012-28,217,055 \\
\text { chr6: } 35,309,717-35,309,760 \\
\text { chr23: } 9,282,363-9,282,406\end{array}$} & CG TGGCCCTGGAGGAGCACTTC CG GGATGA CG ATGATGGCC CG G \\
\hline & HSA & & CG TGGCCCTGGAGGAACACTTC CG AGATGATGATGA CG GCCCTG \\
\hline & BTA & & CG TGGCCCTGGAGGAGCACTTC CG AGACGATGA CG ATGGTCC CG \\
\hline \multirow{3}{*}{ Nrxn2 } & MMU & \multirow{3}{*}{$\begin{array}{c}\text { chr19: } 6,504,094-6,504,133 \\
\text { chr11: } 64,636,291-64,636,330 \\
\text { chr29: } 42,885,070-42,885,110\end{array}$} & CG TTAGGGACCTAACA-CC CG CCCC CG GCAGC CG GATGG CG \\
\hline & HSA & & CG TTAGGGACCTCACA-CC CG CCCCCAGCAGC CG GCTGG CG \\
\hline & BTA & & CG TTAGGGACCTCACACCC CG CCCC CG GCAGC CG GATGGCA \\
\hline
\end{tabular}


Table 1. Cont.

\begin{tabular}{|c|c|c|c|}
\hline Gene & Species & Genomic Localization $^{\text {a }}$ & Sequence Analyzed by Bisulfite Pyrosequencing ${ }^{b}$ \\
\hline \multirow{4}{*}{ Tbx19 } & MMUI & chr1. 165153651-165152509 & CG TC CG GAC CG- \\
\hline & IVIVIU & chr1: 165,153,051-165,153,599 & ACAGTCAC CG CTGGAAGTA CG TCAATGGTGAATGGGTCCC CG \\
\hline & HSA & chr1: $168,291,235-168,291,287$ & $\begin{array}{c}\text { TGTCCCTA- } \\
\text { CG GACAGTCAC CG CTGGAAGTA CG TCAA CG GGGAATGGGTGCC CG }\end{array}$ \\
\hline & BTA & chr3: $253,101-253,049$ & $\begin{array}{l}\text { TGTCCCAA- } \\
\text { CG GACAGTCAT CG CTGGAAGTA CG TCAATGGAGAATGGGTGCCTG }\end{array}$ \\
\hline
\end{tabular}

${ }^{a}$ Genome Reference Consortium Human Build 38 (GRCh38)/hg38, ARS-UCD1.2/bosTau9, and Genome Reference Consortium Mouse Build 38 (GRCm38)/mm10 were used as references. ${ }^{b} \mathrm{CpG}$ sites which are conserved in at least two analyzed species are highlighted by different colors and non-conserved $\mathrm{CpGs}$ are shaded in gray. 
Table 2. Mean methylation of analyzed genomic regions in human, mouse, and bovine sperm.

\begin{tabular}{|c|c|c|c|}
\hline \multirow[t]{2}{*}{ Gene } & \multicolumn{3}{|c|}{ Methylation (\%) \pm Standard Deviation (\%) [Range (\%)] } \\
\hline & HSA $(n=94)$ & BTA $(n=36)$ & MMU $(n=94)$ \\
\hline \multicolumn{4}{|c|}{ Human ageDMRs } \\
\hline NFKB2 & $44.5 \pm 10.0[22.3-64.0]$ & n.d. & $5.6 \pm 0.8[3.8-7.6]$ \\
\hline RASGEF1C & $60.1 \pm 9.1[37.0-81.2]$ & n.d. & $93.5 \pm 0.5[91.8-94.6]$ \\
\hline RPL6 & $36.8 \pm 11.5[15.8-66.5]$ & $95.1 \pm 2.2[89.8-99.6]$ & $95.6 \pm 1.8[90.7-99.0]$ \\
\hline \multicolumn{4}{|c|}{ Bovine ageDMRs } \\
\hline CHD7 & $93.7 \pm 1.0[90.6-96.2]$ & $53.0 \pm 18.1[18.2-83.4]$ & $57.9 \pm 4.2[46.9-69.5]$ \\
\hline HDAC11 & $4.7 \pm 1.2[2.5-8.5]$ & $89.3 \pm 3.0[78.6-92.9]$ & n.d. \\
\hline PAK1 & $1.0 \pm 0.1[0.6-1.7]$ & $48.1 \pm 13.1[18.3-75.0]$ & $1.9 \pm 0.6[0.5-5.4]$ \\
\hline PTK2B & $94.0 \pm 3.0[90.3-100]$ & $66.6 \pm 8.7[48.1-80.4]$ & n.d. \\
\hline \multicolumn{4}{|c|}{ Mouse ageDMRs } \\
\hline Def6 & $93.1 \pm 1.9[86.8-99.0]$ & $97.9 \pm 0.8[96.0-99.7]$ & $43.5 \pm 5.9[31.4-60.7]$ \\
\hline Nrxn2 & $82.6 \pm 3.8[51.8-87.0]$ & $91.1 \pm 2.1$ [86.3-95.1] & $61.3 \pm 8.1[42.0-81.3]$ \\
\hline Tbx19 & $93.3 \pm 1.0[86.9-94.7]$ & $94.8 \pm 1.6[88.0-97.2]$ & $71.1 \pm 3.2[64.2-84.4]$ \\
\hline
\end{tabular}

Table 3. Correlations between donor age and mean methylation in human, bovine, and mouse sperm.

\begin{tabular}{|c|c|c|c|c|c|c|}
\hline \multirow[t]{2}{*}{ Gene } & \multicolumn{2}{|c|}{ HSA $(n=94)$} & \multicolumn{2}{|c|}{ BTA $(n=36)$} & \multicolumn{2}{|c|}{ MMU $(n=94)$} \\
\hline & Pearson's $r$ & $p$ & $\begin{array}{c}\text { Spearman's } \\
\rho\end{array}$ & $p$ & $\begin{array}{c}\text { Spearman's } \\
\rho\end{array}$ & $p$ \\
\hline \multicolumn{7}{|c|}{ Human ageDMRs } \\
\hline NFKB2 & -0.37 & 0.002 & \multicolumn{2}{|c|}{ n.d. } & 0.22 & 0.04 \\
\hline RASGEF1C & -0.28 & 0.03 & \multicolumn{2}{|c|}{ n.d } & -0.10 & 0.33 \\
\hline RPL6 & -0.25 & 0.05 & 0.37 & 0.03 & 0.07 & 0.53 \\
\hline \multicolumn{7}{|c|}{ Bovine ageDMRs } \\
\hline CHD7 & 0.09 & 0.47 & 0.75 & $<0.0001$ & 0.11 & 0.31 \\
\hline HDAC11 & -0.22 & 0.08 & 0.50 & 0.002 & \multicolumn{2}{|c|}{ n.d. } \\
\hline PAK1 & -0.01 & 0.92 & 0.68 & $<0.0001$ & -0.06 & 0.56 \\
\hline PTK2B & 0.11 & 0.42 & 0.53 & 0.001 & \multicolumn{2}{|c|}{ n.d. } \\
\hline \multicolumn{7}{|c|}{ Mouse ageDMRs } \\
\hline Def6 & 0.10 & 0.42 & 0.40 & 0.02 & -0.69 & $<0.0001$ \\
\hline Nrxn2 & -0.18 & 0.16 & -0.15 & 0.37 & -0.45 & $<0.0001$ \\
\hline Tbx19 & -0.05 & 0.71 & 0.49 & 0.003 & -0.33 & 0.001 \\
\hline
\end{tabular}


Human DMRs
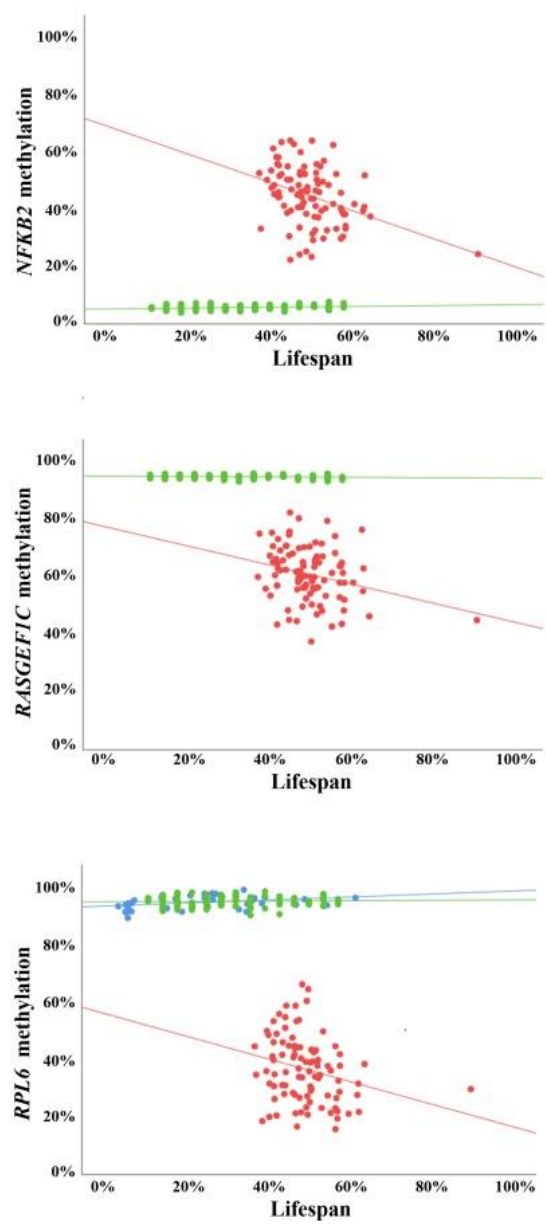

Human sperm sample

Bovine

Mouse
Bovine DMRs
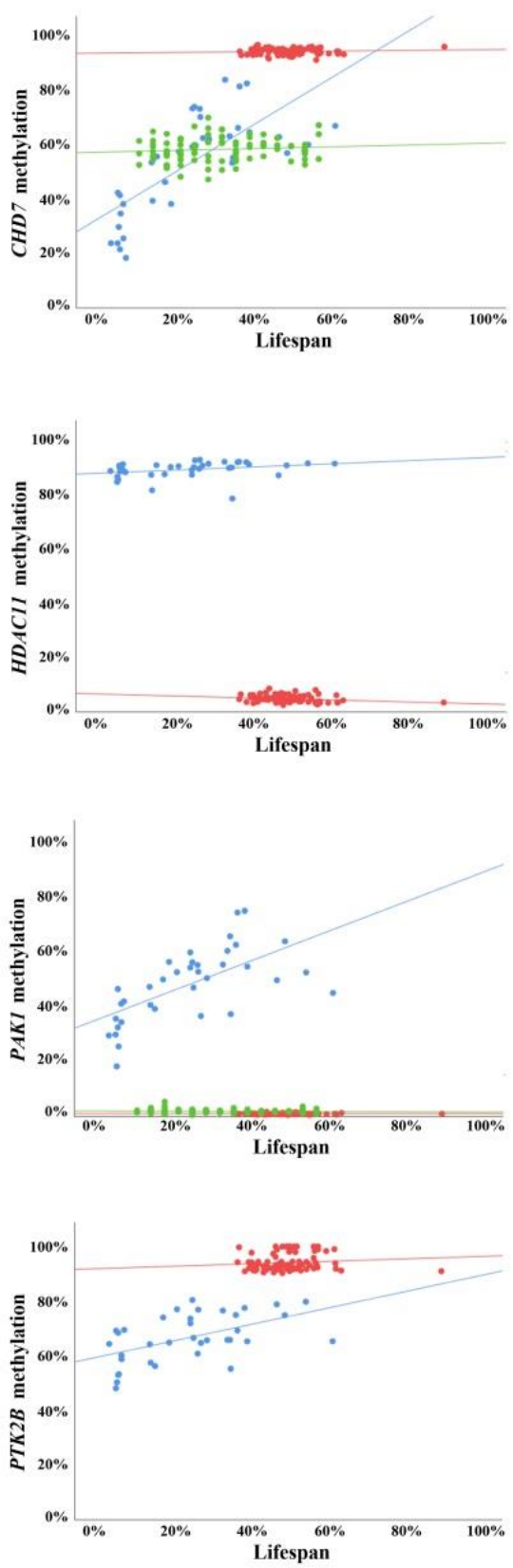

Mouse DMRs
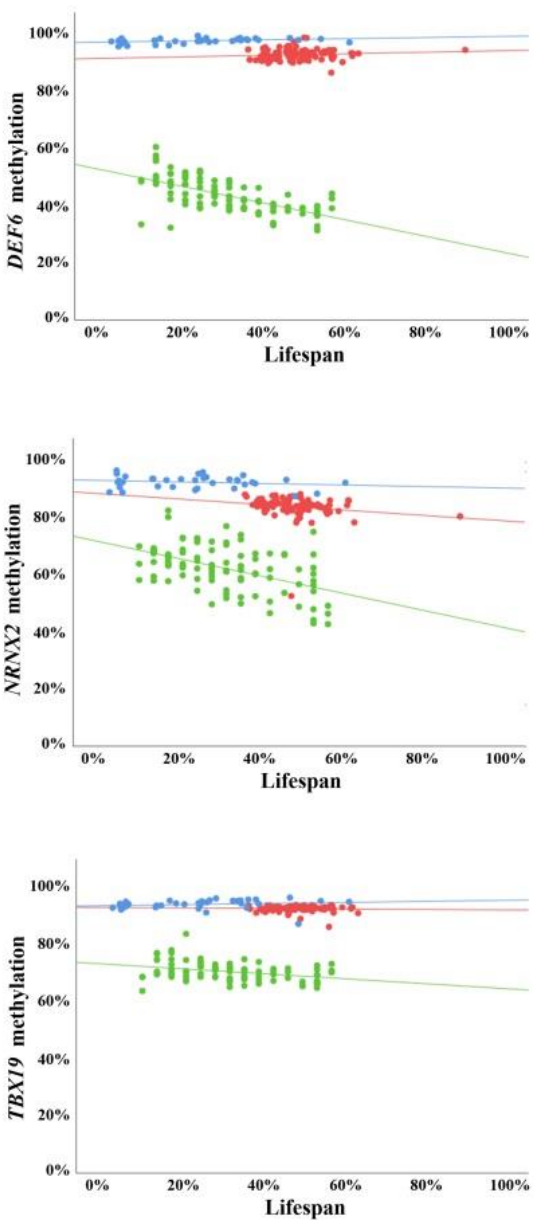

Figure 1. Scatter plots showing the correlations between average regional methylation, including conserved and non-conserved CpGs ( $\mathrm{y}$-axis in \%) and donor age (x-axis in percentage of lifespan) in 94 human sperm samples (indicated by red dots), 36 bovine samples (blue dots), and 94 mouse samples (green dots). NFKB2, RASGEF1C, and RPL6 are endowed with human-specific sperm ageDMRs; CHD7, HDAC11, PAK1, and PTK2B with bovine-specific sperm ageDMRs; and Def6, Nrxn2, and $T b \times 19$ with mouse-specific sperm ageDMRs.

\section{Discussion}

The main finding of this study is that sperm methylation patterns found in generegulatory regions that are susceptible to paternal age effects are largely species-specific. One can speculate that the species-specific paternal age effects on the sperm epigenome and their possible impact on gene regulation in the next generation [12] may be part of an evolutionarily conserved mechanism, to allow environmental adaptation in a species- 
specific manner. Overall, species differences in mammalian sperm epigenomes may be a driving force to shape lineage-specific complex phenotypes, e.g., brain functioning in humans, and lipid storage and metabolism in cattle [31].

Mammalian sperm show a bimodal distribution of hypermethylated and hypomethylated regions, with global methylation levels between $70 \%$ and $80 \%$ [31-33]. DNA methylation is important to prevent retrotransposon activity and genome instability in germ cells [34]. A seven-species comparison of mammalian sperm methylomes revealed that both the number and size of hypomethylated regions in sperm expanded during epigenome evolution [32]. Hypomethylated regions are frequently observed in regulatory elements, including promoters, enhancers, and insulators [35]. A fraction of methylation marks found on regulatory genetic elements, which escape genome-wide reprogramming in the germline [36] and after fertilization [37], are primary candidates for transgenerational epigenetic inheritance. The majority of hypomethylated sperm promoters are conserved across species [32] and may be involved in important biological processes in embryo development [31]. In contrast, evolutionarily conserved hypermethylated sperm promoters may be critically involved in the silencing of immune genes for adherence and implantation of the embryo in the uterine wall.

Since methylated, and to some extent also non-methylated, CpGs are mutational hotspots [28,29], the vast majority of $\mathrm{CpG}$ sites have diverged during mammalian evolution. Only about 400,000 CpG sites, mainly in coding regions, have been conserved across mammalian species [32]. Our results show that paternal age effects on sperm gene regulation are driven by both conserved and non-conserved CpGs in the target regions. This is not unexpected because the methylation of neighboring CpGs is highly interdependent and phenotypic effects through altered gene regulation are usually mediated by methylation changes at the regional level [30]. Only one of 30 studied evolutionarily conserved CpG sites was subject to paternal age effects (in the same direction) in two analyzed species (mouse and human), whereas the regional age effect was only observed in the mouse. It is tempting to speculate that the age-related loss of methylation at this particular CpG (MMU19:6,504,094) site in the mouse Nrxn2 coding region served as a nucleation point for regional hypomethylation in the mouse. The lineage-specific formation of new hypomethylated regions, and an extension of existing hypomethylated regions, has been observed in mammalian sperm epigenome evolution [32].

Consistent with earlier comparisons of human, bovine, and mouse sperm methylomes [31], we also observed dramatic interspecies differences in the methylation levels of orthologous regions. In species showing a significant age effect, the methylation level of a given regulatory region was usually in the medium range $(20-80 \%)$, and there was considerable methylation variation between individuals. The orthologous regions of the other two analyzed species were either hypermethylated or, less frequently, hypomethylated. Hyper- and hypomethylated regions exhibited less methylation variation and, rarely, a significant age effect (i.e., bovine HDAC11).

Although only a limited number of regulatory genes were analyzed, it is striking that selected human ageDMRs (NFKB2, RASGEF1C, and RPL6) lose methylation, whereas bovine DMRs (RPL6, CHD7, HDAC11, PAK1, PTK2B, DEF6, and TBX19) gain methylation with age. This is consistent with earlier studies on paternal aging effects in humans [4] and bovines [20]. In mouse sperm, three DMRs (Def6, Nrxn2, and Tbx19) lost, and one hypomethylated DMR ( $N f k b 2$ ) gained methylation with age. One region (RPL6) showed opposite methylation changes in humans and bovines, one region (NFKB2) between humans and mice, and two regions (DEF6 and TBX19) between bovines and mice. Provided that these age-related methylation changes are transmitted to the next generation, increased paternal age may be associated with gene activation in humans and mice, and gene silencing in bovines. 


\section{Conclusions}

Although it is difficult to extrapolate the findings from candidate gene studies to the entire (epi)genome, our results reveal that, in contrast to rDNA and other repetitive elements [2], the paternal age effects on sperm methylation of individual genes are largely species-specific. Neither average methylation nor age-related methylation changes in orthologous regulatory regions are evolutionarily conserved. We hypothesize that sperm methylation and the regulation of individual genes in the resulting embryo may be part of an evolutionary mechanism to allow environmental adaptations in a species-specific manner.

Our study is restricted to gene-regulatory regions which are conserved between species. Age-related methylation changes involve neighboring conserved and non-conserved $\mathrm{CpG}$ sites. One advantage of our study is that bisulfite pyrosequencing is a highly accurate method (compared to genome-wide methylation screens) to quantify methylation at both the single-CpG and the regional level. The methylation differences between technical replicates (including bisulfite conversion) of our assays were in the order of 1-2 percentage points. Our assays allow one to analyze a relatively high number of sperm samples at reasonable cost and expenditure of time. This made it possible to detect even minor, but significant, age effects in hypomethylated (i.e., mouse $N f k b 2$ ) and hypermethylated (bovine RPL6, DEF6, and TBX19) regions with low methylation variation, which may escape detection in genome-wide screens. However, genes with medium methylation levels and large methylation variations appear to be more susceptible to paternal aging. This should allow the prioritization of candidate genes from genome-wide methylome data sets for future studies on sperm aging.

The male germline-specific reprogrammed sperm epigenome [25] is fundamentally different from the epigenomes of somatic cells. Although direct experimental evidence is lacking, it is unlikely that the identified sperm ageDMRs also exist in somatic tissues. The observed age-related sperm methylation changes in single copy genes were in the order of several percentage points and were comparable to those in previous studies [1,6]. Because of the enormous variation among individuals, there was considerable overlap in the methylation levels of a given gene in a given species between older and younger sperm donors. Small effect size does not necessarily exclude the functional importance of sperm methylation marks. Consistent with a multifactorial model, multiple age-related epigenetic changes may contribute to the developmental competence of the resulting embryos and the shaping of the health and disease of the offspring. Future studies on methylation and expression of the identified genes in embryonic, fetal, and adult tissues from the offspring of old vs. young fathers may directly demonstrate an impact of sperm age DMRs on the next generation.

Supplementary Materials: The following are available online at https: / www.mdpi.com/article/ 10.3390/cells11040731/s1. Table S1: Genes with ageDMRs, identified by RRBS in human, bovine, and mouse sperm samples. Table S2: PCR and sequencing primers for bisulfite pyrosequencing in human, bovine, and mouse sperm. Table S3: Correlation between single CpG methylation and donor age in human, bovine, and mouse sperm. Figure S1: Scatter plots showing the correlations between methylation of individual evolutionarily conserved CpGs and donor age in human, bovine, and mouse sperm samples.

Author Contributions: Conceptualization, T.H. (Thomas Haaf); supervision, writing—original draft preparation, T.H. (Thomas Haaf) and R.P.; investigation, validation, visualization, data curation and analysis, A.P., M.O.S. and R.P.; RRBS methodology, data analysis, L.B. and M.D.; resources, writing-review and editing, M.S., T.H. (Thomas Hahn), F.Z., G.E.P. and H.N. All authors have read and agreed to the published version of the manuscript.

Funding: This study was supported by the German Research Foundation (grant no. HA 1374/19-1), the EU Horizon 2020 Research and Innovation Programme (grant no. 692185, acronym ERAofART and grant no. 836421, acronym NeuroAPA), and the National Science Centre (GA no. 2019/35/B/NZ4/03547). 
Institutional Review Board Statement: This study was conducted according to the guidelines of the Declaration of Helsinki and approved by the Ethics Committee at the Medical Faculty of the University of Würzburg (no. 117/11 and 212/15).

Informed Consent Statement: All participants provided informed consent in accordance with the Declaration of Helsinki.

Data Availability Statement: The data underlying this work are available in the article and its online supplementary material.

Acknowledgments: We thank all the couples participating in the study. We thank J. Pott and S. Akabanes from Masterrind, Verden, Germany for providing the bovine semen samples.

Conflicts of Interest: The authors declare no conflict of interest.

\section{References}

1. Potabattula, R.; Dittrich, M.; Böck, J.; Haertle, L.; Müller, T.; Hahn, T.; Schorsch, M.; Hajj, N.E.; Haaf, T. Allele-specific methylation of imprinted genes in fetal cord blood is influenced by cis-acting genetic variants and parental factors. Epigenomics 2018, 10, 1315-1326. [CrossRef] [PubMed]

2. Potabattula, R.; Zacchini, F.; Ptak, G.E.; Dittrich, M.; Müller, T.; El Hajj, N.; Hahn, T.; Drummer, C.; Behr, R.; Lucas-Hahn, A.; et al. Increasing methylation of sperm rDNA and other repetitive elements in the aging male mammalian germline. Aging Cell 2020, 19, e13181. [CrossRef] [PubMed]

3. Jaenisch, R.; Bird, A. Epigenetic regulation of gene expression: How the genome integrates intrinsic and environmental signals. Nat. Genet. 2003, 33, 245-254. [CrossRef] [PubMed]

4. Jenkins, T.G.; Aston, K.I.; Pflueger, C.; Cairns, B.R.; Carrell, D.T. Age-associated sperm DNA methylation alterations: Possible implications in offspring disease susceptibility. PLoS Genet. 2014, 10, e1004458. [CrossRef]

5. Aston, K.I.; Uren, P.J.; Jenkins, T.G.; Horsager, A.; Cairns, B.R.; Smith, A.D.; Carrell, D.T. Aberrant sperm DNA methylation predicts male fertility status and embryo quality. Fertil. Steril. 2015, 104, 1388-1397. [CrossRef]

6. Atsem, S.; Reichenbach, J.; Potabattula, R.; Dittrich, M.; Nava, C.; Depienne, C.; Böhm, L.; Rost, S.; Hahn, T.; Schorsch, M.; et al Paternal age effects on sperm FOXK1 and KCNA7 methylation and transmission into the next generation. Hum. Mol. Genet. 2016, 25, 4996-5005.

7. Nelson, S.; Telfer, E.E.; Anderson, R.A. The ageing ovary and uterus: New biological insights. Hum. Reprod Update 2013, 9, 67-83. [CrossRef]

8. Luna, M.; Finkler, E.; Barritt, J.; Bar-Chama, N.; Sandler, B.; Copperman, A.B.; Grunfeld, L. Paternal age and assisted reproductive technology outcome in ovum recipients. Fertil. Steril. 2009, 92, 1772-1775. [CrossRef]

9. Crow, J.F. The origins, patterns and implications of human spontaneous mutation. Nat. Rev. Genet. 2000, 1, 40-47. [CrossRef]

10. De Kluiver, H.; Buizer-Voskamp, J.E.; Dolan, C.V.; Boomsma, D.I. Paternal age and psychiatric disorders: A review. Am. J. Med. Genet. Part. B Neuropsychiat. Genet. 2017, 174, 202-213. [CrossRef]

11. Bennett-Baker, P.E.; Wilkowski, J.; Burke, D.T. Age-associated activation of epigenetically repressed genes in the mouse. Genetics 2003, 165, 2055-2062. [CrossRef] [PubMed]

12. Milekic, M.H.; Xin, Y.; O’Donnell, A.; Kumar, K.K.; Bradley-Moore, M.; Malaspina, D.; Moore, H.; Brunner, D.; Ge, Y.; Edwards, J.; et al. Age-related sperm DNA methylation changes are transmitted to offspring and associated with abnormal behavior and dysregulated gene expression. Mol. Psychiatry 2015, 20, 995-1001. [CrossRef] [PubMed]

13. Rattan, S.I. Synthesis, modifications, and turnover of proteins during aging. Exp. Gerontol. 1996, 31, 33-47. [CrossRef]

14. Tiku, V.; Antebi, A. Nucleolar function in lifespan regulation. Trends Cell Biol. 2018, 28, 662-672. [CrossRef] [PubMed]

15. Wang, M.; Lemos, B. Ribosomal DNA harbors an evolutionarily conserved clock of biological aging. Genome Res. 2019, 29, 325-333. [CrossRef]

16. Jenkins, T.G.; Aston, K.I.; Cairns, B.; Smith, A.; Carrell, D.T. Paternal germ line aging: DNA methylation age prediction from human sperm. BMC Genomics 2018, 19, 763. [CrossRef]

17. Laurentino, S.; Cremers, J.F.; Horsthemke, B.; Tüttelmann, F.; Czeloth, K.; Zitzmann, M.; Pohl, E.; Rahmann, S.; Schröder, C.; Berres, S.; et al. A germ cell-specific ageing pattern in otherwise healthy men. Aging Cell 2020, 19, e13242. [CrossRef]

18. Pisarek, A.; Pospiech, E.; Heidegger, A.; Xavier, C.; Papiez, A.; Piniewska-Rog, D.; Kalamara, V.; Potabattula, R.; Bochenek, M.; Sikora-Polaczek, M.; et al. Epigenetic age prediction in semen-marker selection and model development. Aging 2021, 13, 19145-19164. [CrossRef]

19. Takeda, K.; Kobayashi, E.; Akagi, S.; Nishino, K.; Kaneda, M.; Watanabe, S. Differentially methylated CpG sites in bull spermatozoa revealed by human DNA methylation arrays and bisulfite analysis. J. Reprod. Dev. 2017, 63, 279-287. [CrossRef]

20. Takeda, K.; Kobayashi, E.; Nishino, K.; Imai, A.; Adachi, H.; Hoshino, Y.; Iwao, K.; Akagi, S.; Kaneda, M.; Watanabe, S. Age-related changes in DNA methylation levels at CpG sites in bull spermatozoa and in vitro fertilization-derived blastocyst-stage embryos revealed by combined bisulfite restriction analysis. J. Reprod. Dev. 2019, 65, 305-312. [CrossRef]

21. Lambert, S.; Blondin, P.; Vigneault, C.; Labrecque, R.; Dufort, I.; Sirard, M.A. Spermatozoa DNA methylation patterns differ due to peripubertal age in bulls. Theriogenology 2018, 106, 21-29. [CrossRef] [PubMed] 
22. Xie, K.; Ryan, D.P.; Pearson, B.L.; Henzel, K.S.; Neff, F.; Vidal, R.O.; Hennion, M.; Lehmann, I.; Schleif, M.; Schröder, S.; et al. Epigenetic alterations in longevity regulators, reduced life span, and exacerbated aging-related pathology in old father offspring mice. Proc. Natl. Acad. Sci. USA 2018, 15, E2348-E2357. [CrossRef] [PubMed]

23. Yoshizaki, K.; Kimura, R.; Kobayashi, H.; Oki, S.; Kikkawa, T.; Mai, L.; Koike, K.; Mochizuki, K.; Inada, H.; Matsui, Y.; et al. Paternal age affects offspring via an epigenetic mechanism involving REST/NRSF. Embo Rep. 2021, 22, e51524. [CrossRef] [PubMed]

24. Lee, H.Y.; Jung, S.E.; Oh, Y.N.; Choi, A.; Yang, W.I.; Shin, K.J. Epigenetic age signatures in the forensically relevant body fluid of semen: A preliminary study. Forensic. Sci. Int. Genet. 2015, 19, 28-34. [CrossRef]

25. Reik, W.; Dean, W.; Walter, J. Epigenetic reprogramming in mammalian development. Science 2001, 293, 1089-1093. [CrossRef]

26. Horvath, S. DNA methylation age of human tissues and cell types. Genome Biol. 2013, 14, 3156. [CrossRef]

27. Field, A.E.; Robertson, N.A.; Wang, T.; Havas, A.; Ideker, T.; Adams, P.D. DNA methylation clocks in aging: Categories, causes, and consequences. Mol. Cell 2018, 71, 882-895. [CrossRef]

28. Pfeifer, G.P. Mutagenesis at methylated CpG sequences. Curr. Top. Microbiol. Immunol. 2006, 301, $259-281$.

29. Behringer, M.G.; Hall, D.W. Genome-wide estimates of mutation rates and spectrum in Schizosaccharomyces pombe indicate CpG sites are highly mutagenic despite the absence of DNA methylation. G3 2015, 6, 149-160. [CrossRef]

30. Weber, M.; Hellmann, I.; Stadler, M.B.; Ramos, L.; Pääbo, S.; Rebhan, M.; Schübeler, D. Distribution, silencing potential and evolutionary impact of promoter DNA methylation in the human genome. Nat. Genet. 2007, 39, 457-466. [CrossRef]

31. Fang, L.; Zhou, Y.; Liu, S.; Jiang, J.; Bickhart, D.M.; Null, D.J.; Li, B.; Schroeder, S.G.; Rosen, B.D.; Cole, J.B.; et al. Comparative analyses of sperm DNA methylomes among human, mouse and cattle provide insights into epigenomic evolution and complex traits. Epigenetics 2019, 14, 260-276. [CrossRef] [PubMed]

32. Qu, J.; Hodges, E.; Molaro, A.; Gagneux, P.; Dean, M.D.; Hannon, G.J.; Smith, A.D. Evolutionary expansion of DNA hypomethylation in the mammalian germline genome. Genome Res. 2018, 28, 145-158. [CrossRef] [PubMed]

33. Molaro, A.; Hodges, E.; Fang, F.; Song, Q.; McCombie, W.R.; Hannon, G.J.; Smith, A.D. Sperm methylation profiles reveal features of epigenetic inheritance and evolution in primates. Cell 2011, 146, 1029-1041. [CrossRef] [PubMed]

34. Yoder, J.A.; Walsh, C.P.; Bestor, T.H. Cytosine methylation and the ecology of intragenomic parasites. Trends Genet. 1997, 13, 335-340. [CrossRef]

35. Jones, P.A. Functions of DNA methylation: Islands, start sites, gene bodies and beyond. Nat. Rev. Genet. 2012, 13, 484-492. [CrossRef]

36. Tang, W.W.; Dietmann, S.; Irie, N.; Leitch, H.G.; Floros, V.I.; Bradshaw, C.R.; Hackett, J.A.; Chinnery, P.F.; Surani, M.A. A unique gene regulatory network resets the human germline epigenome for development. Cell 2015, 161, 1453-1467. [CrossRef]

37. Wang, L.; Zhang, J.; Duan, J.; Gao, X.; Zhu, W.; Lu, X.; Yang, L.; Zhang, J.; Li, G.; Ci, W.; et al. Programming and inheritance of parental DNA methylomes in mammals. Cell 2014, 157, 979-991. [CrossRef] 